\title{
SUAUGUSIŲJŲ ATSIGAVIMO PO AUSŲ, NOSIES, GERKLĖS IR UROLOGINIŲ OPERACIJŲ KOKYBĖS LYGMENS IৃVERTINIMAS
}

\author{
Eglė Glumbakaitė ${ }^{1}$, Vytautas Ragaišis ${ }^{2}$, Andrius Macas ${ }^{3}$ \\ ${ }^{1}$ Lietuvos sveikatos moksly universitetas, Medicinos akademija, Medicinos fakultetas, \\ ${ }^{2}$ Lietuvos sveikatos mokslu universitetas, Kauno klinikos, Anesteziologijos klinika, \\ ${ }^{3}$ Lietuvos sveikatos moksly universitetas, Medicinos akademija, Medicinos fakultetas, \\ Anesteziologijos klinika
}

Raktažodžiai: atsigavimo kokybė, QoR-15 klausimynas, suaugusieji, poanestezinè priežiūra, ANG, urologinès operacijos.

\section{Santrauka}

Poanestezinė priežiūra tai stebėsenos ir priežiūros, profilaktikos ir gydymo priemonių visuma, kurios pagrindinis tikslas - užtikrinti pacientų saugumą ankstyvuoju poanesteziniu laikotarpiu, ịskaitant ankstyvų komplikacijų atpažinimą ir skubų jų gydymą, siekiant išvengti nepageidaujamų baigčių.

Atsigavimo kokybė QoR (angl. quality of recovery, sutr.) ir jos ịvertinimas ankstyvajame periode netrukus po anestezijos ir operacijos yra svarbus paciento pooperacinès sveikatos būklès ịvertinimo kriterijus. Vertinant paciento būklę, dažnai apsiribojama tik klinikinių ir paraklinikinių simptomų įvertinimu: organų disfunkcijos, chirurginių komplikacijų, laboratorinių tyrimų ir kt. Rečiau analizuojama, kaip pacientas vertina savijautą, pasitenkinimą intervencija.

2013 m. idiegtas QoR-15 klausimynas, naudojamas ankstyvojo poanestezinio periodo atsigavimo kokybès ivvertinimui. I pateiktus klausimus atsako pacientas. Tai paprastesnè ir trumpesnè anksčiau pasiūlyto ir sudètingesnio QoR-40 klausimyno versija. QoR-15 klausimyne panašūs psichometriniai kriterijai kaip ir QoR-40, tačiau QoR-15 klausimyno užpildymas yra paprastesnis, o klausimynas keturis kartus trumpesnis. Užpildyti klausimyną užtrunka iki 2,5 minutès. Be to, autoriai nurodo, kad suvokti QoR-40 klausimyną kai kuriems pacientams gali būti per sunku, nors jis ir yra išsamesnis. QoR-15, ekspertų nuomone, yra patikimas, vertingas, lengvai ir greitai užpildomas, nesunkiai igyvendinamas, todèl gali būti naudojamas perioperacinio periodo klinikiniuose tyrimuose, siekiant ịvertinti paciento būseną, pasitenkinimą ir šio periodo medicininių paslaugų kokybę. Klau- simynai, atspindintys pacientų nuomonę apie atsigavimo kokybę, rekomenduojami ne tik gydymo centruose, bet ir regioninèse ligoninèse.

\section{Ivadas}

I intensyviosios terapijos skyrius po chirurginių operacijų patenka daug pacientų, kuriems reikia intensyvaus stebejjimo arba slaugos, o ne intensyviosios terapijos. Šiam tikslui labiausiai tinka poanestezinès priežiūros paslauga. Riboto paslaugos laiko (iki 24 val.) užtenka pacientą saugiai perkelti ị profilinị chirurgijos skyrių, remiantis klinikoje reglamentuotais perkèlimo kriterijais [1].

Literatūroje nurodoma, kad netrukus po anestezijos ir operacijos vertinant pacientų būklę, dažniausiai vertinami jau minèti gydytojams svarbūs klinikiniai, laboratoriniai ir kiti kriterijai, o paciento emocinè savijauta, pasitenkinimo lygmuo ankstyvajame poanesteziniame ir operacijos periode netiriamas [2-8]. Paciento atsigavimo kokybès lygmens tyrimai ir vertinimas tampa vis svarbesni. JAV ir JK skatinamos aukštos kokybès studijos, siekiant užtikrinti kuo geresnį pacientų pasitenkinimą atsigavimo kokybe. Jau pradeda funkcionuoti speciali programa: ligoninès privalo informuoti koordinuojantị centrą, kaip pacientai vertina savo poanestezinio atsigavimo kokybę. Paciento pateiktas atsigavimo kokybès ịvertinimas leidžia atsižvelgti ne tik ị ligos baigties, gydymo kaštų, saugių gydymo būdų naudojimo aspektus, bet ir i pacientų pasitenkinimo lygmenį. Tokia praktika svarbi ne tik pagrindiniuose gydymo centruose, bet ir regionuose [8].

Paciento būklès įvertinimui ankstyvuoju poanesteziniu periodu naudojamos įvairios skalès. Dažnai naudojamos QoR-15 ir išsamesnė QoR-40 [1-5]. Pastarųų panašumai ir skirtumai jau buvo trumpai aptarti. Autoriai nurodo, kad klinikinejje praktikoje per mažai dèmesio skiriama šio periodo svarbai ligos baigties požiūriu [3]. Savo darbe naudojome QoR-15 skalę, nes ji yra pa- 
tikima, greitai užpildoma ir nesunkiai suprantama [2-7].

Dèl galimų ịvairaus pobūdžio komplikacijų ankstyvuoju poanesteziniu periodu ir didelio pacientų srauto intensyviosios terapijos skyriuose, LSMUL Kauno klinikose nuo $2018 \mathrm{~m}$. veikia poanestezinès priežiūros poskyris (PAPP). Mes tyrème šio periodo pacientus po ausų, nosies, gerklès (ANG) ir urologinių anestezijų bei operacijų. Siekta ịvertinti pacientų atsigavimo kokybès pasitenkinimo lygmenį ankstyvojo poanestezinio pooperacinio periodo paslaugomis, kad būtų galima gerinti PAPP paslaugų kokybę, atsižvelgiant i pacientų siūlymus.

Tyrimo tikslas - remiantis QoR-15 klausimynu, nustatyti suaugusių pacientų atsigavimo kokybès lygmenị poanestezinès priežiūros poskyryje po ausų, nosies, gerklès (ANG) ir urologinių anestezijų ir operacijų.

\section{Darbo uždaviniai}

1. Išsiaiškinti QoR-15 klausimyno tinkamumą įvertinti atsigavimo kokybės lygmenį mūsų tirtiems PAPP pacientams.

2. Išanalizuoti suaugusių pacientų atsigavimo kokybę PAPP po ANG ir urologinių anestezijų ir operacijų.

3. Išsiaiškinti, kokie atsigavimo kokybės aspektai pagal QoR-15 klausimyną buvo įvertinti blogiausiai ir pasiūlyti paslaugų kokybės gerinimo priemones

4. Ištirti pacientų nuomonę dèl PAPP reikalingumo.

\section{Tyrimo objektas, medžiaga ir metodai}

Suplanuotas perspektyvinis tyrimas. Tyrimui atlikti gautas LSMU Bioetikos centro leidimas (Nr. BEC-MF-21). Analizuota LSMU Kauno klinikų poanestezinès priežiūros poskyrio pacientų, užpildžiusių QoR-15 klausimyną, nuomonè. Studijuoti duomenų bazėse esantys straipsniai, kuriuose išnagrinètos dažniausios ankstyvojo poanestezinio periodo priežiūros problemos, ịvertintos straipsniuose pateikiamos išvados, išanalizuotos panaudojus standartizuotus klausimynus ir skales.

Duomenys atsigavimo kokybės lygmens įvertinimui poanestezinès priežiūros poskyryje po ANG ir urologinių anestezijų ir operacijų rinkti nuo $2019 \mathrm{~m}$. spalio iki $2020 \mathrm{~m}$. vasario mènesio. Minimalus imties tūris, kad rezultatai būtų statistiškai patikimi, ne mažiau kaip 30 pacientų.

Itraukimo kriterijai: pacientai, kuriems buvo taikyta bendriné nejautra; operacijos trukmé trumpesnè nei 4 valandos; operacinèje ekstubuoti pacientai; pacientų stebejjimo PAPP trukmè 2-12 val. Perkèlimas buvo atliekamas remiantis protokolu.

Atmetimo kriterijai: pacientai, turintys kognityviniu (suvokimo) sutrikimų; pacientai, jaunesni nei 18 metų.

Pasirinktas plačiai naudojamas ir, ekspertų vertinimu, patikimas QoR-15 klausimynas, kuris, nors ir naudojamas daugelyje Europos ir pasaulio šalių, anksčiau ị lietuvių kalbą išverstas nebuvo. QoR-15 klausimynas yra lengvai suprantamas, neilgas, todèl pacientams nesunkiai pavyko atsakyti ì visus 15 klausimų. Klausimyno pildymo trukmè mūsų pacientams svyravo nuo 1,5 iki 7 minučių. Poanestezinès atsigavimo kokybès lygmens vertinimui PAPP atsitiktiniu būdu atrinkti ir apklausiami pacientai po ịvairių ANG ir urologinių operacijų: sinusų, nosies, burnaryklès, gerklų, inkstų, šlapimo pūslès, šlapimtakių.

Penkiolikoje klausimų buvo vertinamos penkios paciento sveikatos būklès sritys: skausmas, fizinis komfortas, fizinè nepriklausomybè, psichologinè parama ir emocinè būsena. Kiekvienas klausimas vertinamas 10 balų sistema. Mažiausias balų skaičius yra 0 - labai blogas atsigavimas. Didžiausias balų skaičius 150 - puikus atsigavimas. Gautus kiekybinius rezultatus, remdamiesi literatūra, suskirsteme i 4 grupes kokybès požiūriu:

1. Puikus atsigavimas (136-150 balų).

2. Geras atsigavimas (122-135 balai).

3. Vidutiniškas atsigavimas (90-121 balai).

4. Blogas atsigavimas (0-89 balai) [9].

Pacientai klausimynus užpildydavo patys, prieš pat jų perkèlimą iš PAPP i profilinio chirurginio skyriaus palatas. Papildomai buvo klausiama apie PAPP reikalingumą. Surinkti duomenys buvo apibendrinti ir analizuoti naudojantis SPSS 26.0 programine įranga. Tiriamiesiems požymiams buvo taikomos šios aprašomosios statistikos charakteristikos: vidurkis $(\mathrm{m})$ ir standartinis nuokrypis (SD: amžiaus vidurkiui, QoR-15 kriterijams), absoliutieji skaičiai ir procentai (imčiai, pacientų atsigavimo PAPP pasiskirstymui, pacientų nuomonei apie PAPP reikalingumą įvertinti). Tiriamieji buvo apklausti anoniminiu anketavimo būdu. Atranka patogioji (i tyrimą įtraukti asmenys, sutikę dalyvauti tyrime, gautas raštiškas sutikimas). Tiriamujų konfidencialumas yra užtikrinamas, nes anketa anoniminè. Tyrimo rezultatai skelbiami tik apibendrinti, o duomenys naudojami tik studijų tikslais.

\section{Tyrimo rezultatai ir jų aptarimas}

Tyrime dalyvavo 150 suaugusių pacientų: 63 (42 proc.) vyrai ir 87 (58 proc.) moterys. Vidutinis pacientų amžius $54,59(19,79)$ metai. Dauguma QoR-15 kriteriju - kvėpavimas, maisto poreikis, poilsis, miegas, higiena, bendravimas su šeima, personalo pagalba, darbingumas, savęs kontrolè, gerovès pojūtis, stiprus skausmas, susirūpinimas - ivvertinti geriausiais balais (1 lentelè). Blogiausiai vertinti kriterijai buvo vidutinis skausmas, pykinimas (vėmimas), liūdesys (1 ir 2 lentelè). Sudejus pacientų 15 atsakytų klausimų balus, paaiškejjo, kad dauguma pacientų 138 (92 proc.) pateko i „Gero atsigavimo" grupę, o 10 pacientu (7 proc.) - i grupę „Puikus atsigavimas“. Tik 1 ( 0,6 proc.) tyrimo dalyvis pateko 
i grupę „Vidutinis atsigavimas“. Nebuvo né vieno paciento, kurio ankstyvojo pooperacinio periodo atsigavimas būtų blogas (1 pav.). I papildomą klausimą apie PAPP reikalingumą, 135 (90 proc.) pacientu atsake, kad PAPP yra reikalinga, o 15 (10 proc.) - nebūtina, jie tiesiog galèjo būti perkelti i profilinio chirurgijos skyriaus palatą (2 pav.).

Pacientai turi žinoti ir suprasti, dèl kokių svarbių jų sveikatai priežasčių ir galimų grèsmių po anestezijos ir operacijos jie turi būti perkelti į PAPP, nes pacientų ar jų artimųu susikurti lūkesčiai ir norai gali būti nepakankamai jų pačių suvokti, nerealūs ir nevisiškai ịvykdomi [1-8, 10-17]. Pa-

1 lentelè. Vertinimo kriterijų balų vidurkiai ir standartinis nuokrypis (SD).

\begin{tabular}{|l|c|}
\hline $\begin{array}{l}\text { QoR-15 krite- } \\
\text { rijai }\end{array}$ & $\begin{array}{c}\text { Vertinimo vi- } \\
\text { durkis (+/- SD) }\end{array}$ \\
\hline 1. Kvèpavimas & $9,52(0,8)$ \\
\hline 2. Maistas & $9,26(0,4)$ \\
\hline 3. Poilsis & $9,17(0,8)$ \\
\hline 4. Miegas & $8,66(0,6)$ \\
\hline 5. Higiena & $9,23(0,8)$ \\
\hline $\begin{array}{l}\text { 6. Bendravimas } \\
\text { su šeima }\end{array}$ & $9,88(0,4)$ \\
\hline $\begin{array}{l}\text { 7. Personalo } \\
\text { pagalba }\end{array}$ & $9,92(0,3)$ \\
\hline $\begin{array}{l}\text { 8. Darbingumas } \\
\text { 9. Savęs kontrolè }\end{array}$ & $8,59(0,8)$ \\
\hline $\begin{array}{l}\text { 10. Gerovės } \\
\text { Pojūtis }\end{array}$ & $8,81(0,9)$ \\
\hline $\begin{array}{c}\text { 11. Vidutinis } \\
\text { skausmas }\end{array}$ & $6,64(0,9)$ \\
\hline $\begin{array}{l}\text { 12. Stiprus } \\
\text { skausmas }\end{array}$ & $9,33(1,0)$ \\
\hline $\begin{array}{l}\text { 13. Pykinimas } \\
\text { (vemimas) }\end{array}$ & $7,85(0,8)$ \\
\hline $\begin{array}{l}\text { 14. Susirūpinimas } \\
\text { 15. Liūdesys }\end{array}$ & $8,44(0,9)$ \\
\hline
\end{tabular}

2 lentelè. Blogiausiai vertinti QoR-15 kriterijai, jų balų vidurkiai ir standartinis nuokrypis (SD).

\begin{tabular}{|l|c|}
\hline QoR-15 kriterijai & $\begin{array}{c}\text { Vertinimo } \\
\text { vidurkis (+/- } \\
\text { SD) }\end{array}$ \\
\hline $\begin{array}{l}\text { 1. Vidutinis } \\
\text { skausmas }\end{array}$ & $6,64(0,9)$ \\
\hline $\begin{array}{c}\text { 2. Pykinimas } \\
\text { (vėmimas) }\end{array}$ & $7,85(0,8)$ \\
\hline 3. Liūdesys & $7,25(1,3)$ \\
\hline
\end{tabular}

žymètina, jog pagerèjimo, atsigavimo kokybės ir pasitenkinimo sąvokos yra probleminès, priklausomos nuo daugelio veiksnių, todèl gali būti vertinamos gana subjektyviai ir individualiai. Iki šiol nėra tikslaus šių sąvokų apibrèžimo [5]. Pacientų pasitenkinimą, atsigavimo kokybès lygmenị pagerintų pačių pacientų žinojimas, kokie negalavimai gali būti tuojau po anestezijos ir operacijos, kokios pagalbos jie gali tikètis PAPP, o ne tik tikètis, kad bus išpildyti ju susikurti lūkesčiai $[11,14]$. Atsigavimo kokybès lygmuo priklauso ir nuo operacijos apimties, sudètingumo bei trukmès. Moterys dažniau nurodo blogesnị kokybès lygmenị [2]. Yra autorių, manančių, jog skirtumų ieškojimas tarp lyčių ir rezultatų lyginimas gali sukelti neigiamų asociacijų genderizmo po-

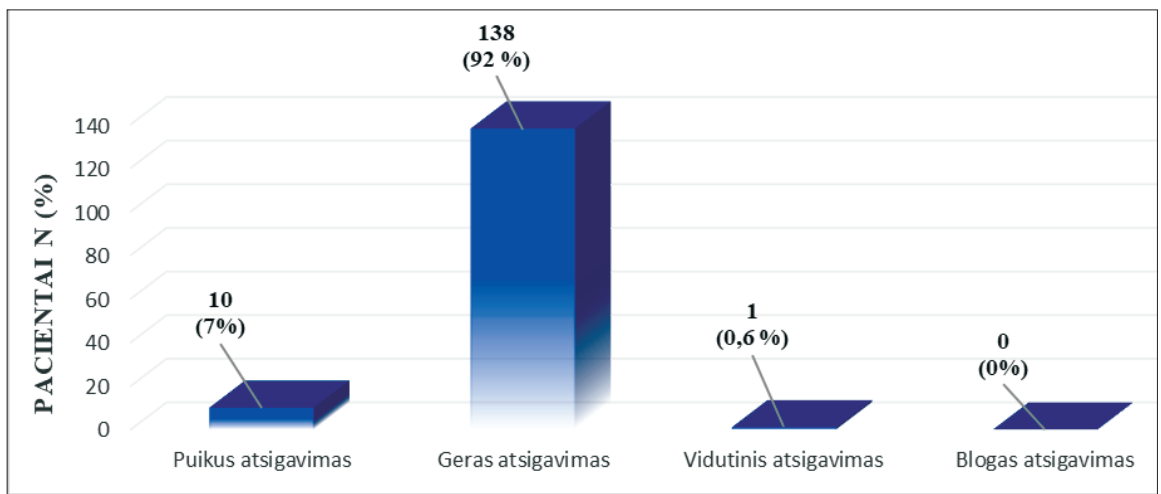

1 pav. Pacientų atsigavimo PAPP pasiskirstymas kokybiniu požiūriu

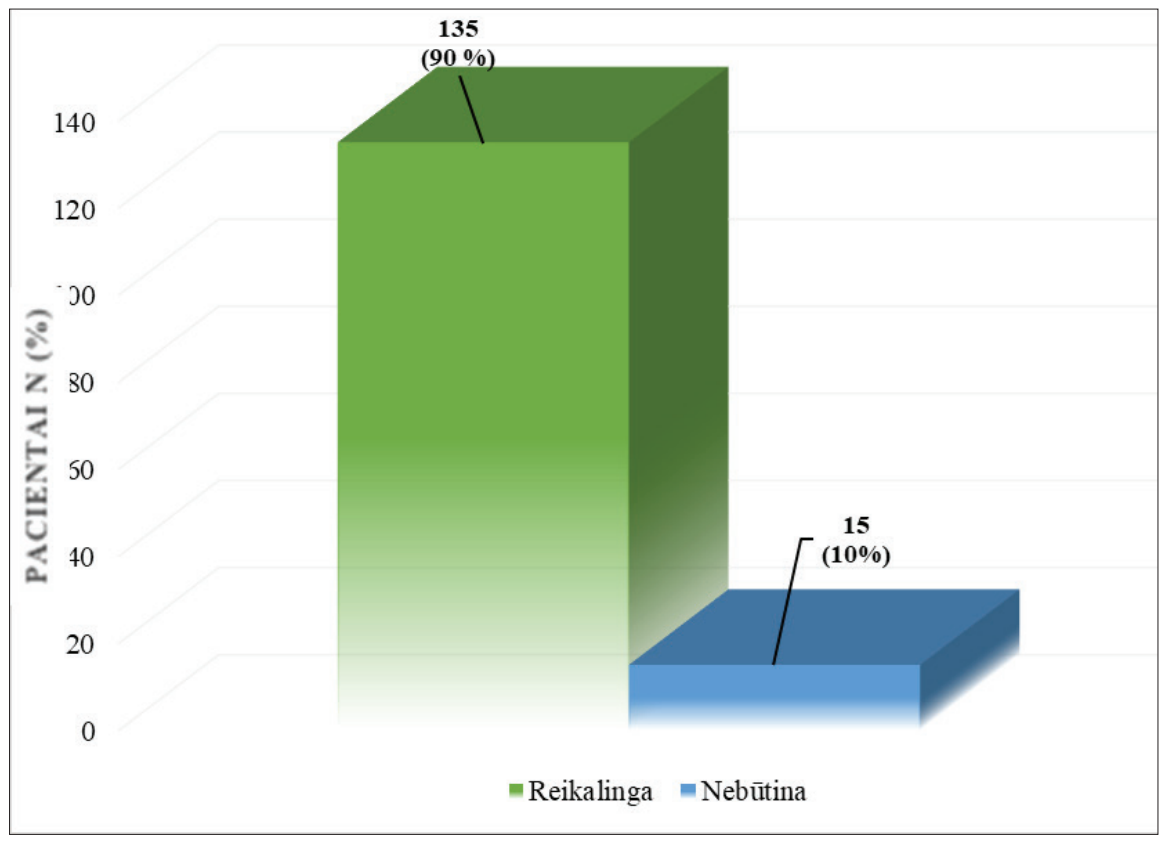

2 pav. Pacientų nuomonė apie PAPP reikalingumą 
žiūriu [11]. Vyresni pacientai mažiau skundžiasi skausmu, pykinimu, vèmimu $[2,3,5]$. Dažniausiai pacientų nusivylimą, blogesnį atsigavimo kokybès vertinimą PAPP sukelia skausmas ir bloga nuotaika $[11,14]$. Šios tendencijos sutampa ir su mūsų tirtų pacientų nusiskundimais. Mūsų pacientų blogesnio pasitenkinimo ir atsigavimo kokybès kriterijus sutapo su pateikiamais literatūroje (vidutinis skausmas, pykinimas (vèmimas), liūdesys). Literatūroje nurodoma, jog siekiant daugiau aiškumo ir tikslumo, vertinant atsigavimo kokybės lygmenį, būtų galima pacientui pateikti klausimą ar savijauta tokia pat, kaip iki operacijos, ar geresnè [5]. Ten pat analizuojama, su kuo reiketų lyginti atsigavimo kokybę PAPP. Jei yra galimybe, paciento savijauta, atsigavimo kokybès lygmuo turètų būti lyginama bent su 24 val. laikotarpio savijauta iki anestezijos ir operacijos. Operacijos dieną anestezijos ir operacijos atsigavimo kokybès vertinimas ir lyginimas nebūtų tikslus ir objektyvus, nes pacientai patiria stresą, ligos sukeltą skausmą ir nepatogumus [11]. Literatūroje teigiama, kad paciento atsigavimo ankstyvajame periode kokybė ir pasitenkinimas priklauso nuo paciento bendros sveikatos būklès ir gretutinių ligų: diabeto, širdies veiklos sutrikimų, nutukimo, neurologinių, psichinių negalavimų ir kt. Gretutinių ligų nebuvimas, greitas išvykimas iš PAPP, lemia didesni paciento pasitenkinimą ir atsigavimo kokybès lygmeni ankstyvuoju periodu.

Nurodoma, kad pakankamai sudètingi ir jautrūs yra QoR15 A dalies 5 ir 8 klausimai (pasirūpinimas tualetu ir higiena, bei darbingumo atsigavimas) [11]. Mūsų tirtiems pacientams žymesnių neaiškumų šie klausimai nesukèlè, o nepatogumų PAPP jie nepatyrè.

Paciento pasitenkinimas atsigavimo kokybe ne visada gali sutapti su sveikatos būklès pagerèjimu. Pasitenkinimui labai svarbu reikiamos informacijos gavimas, fizinis komfortas, emocinis palaikymas, privatumas $[4,11,14]$. Priešingai, ilgalaikis skausmas, pykinimas, vėmimas susijęs su nepasitenkinimu, bloga nuotaika, blogu atsigavimu. Neužtenka klausimyne įrašyti paciento nuomonę, pageidavimus, nusiskundimus. Visuomet skubiai reikia reaguoti $i$ nepasitenkinimą ir skundus ir juos nedelsiant šalinti $[5,15]$. Būtinas kuo geresnis reguliarus (ne tik iki, bet ir PAPP buvimo metu) informacijos teikimas pacientams, kuris turi didelę ịtaką galutiniam geram atsigavimo kokybès lygmens pasiekimui PAPP [16]. Triukšmingumas PAPP yra vienas blogiausiai vertinamų kriterijų. Literatūroje jo reikšmė analizuojama, ieškoma mažinimo būdų, nes tai dažna nepasitenkinimo priežastis, sukelianti poilsio nepakankamumą ir bendrą geros savijautos pojūčio (angl. general well-being) trūkumą, remiantis QoR-15. Pagal PSO rekomendacijas, triukšmas patalpoje neturettų viršyti $40 \mathrm{~dB}$, dar geriau būtų iki $35 \mathrm{~dB}$. Ivairiose klinikose bandoma taikyti 4 ir 2 val. trukmès triukšmo mažinimo programas. Pacientams tai kelia pasitenkinimą. Kartu pastebima, jog tai gali būti ir gana sudètinga problema, ypač jeigu triukšmas kyla už PAPP ribų [17].

135 (90 proc.) mūsų tyrime dalyvavusių pacientų nurodè, kad PAPP reikalinga, 15 (10 proc.) - nebūtina (priežastis - gera būklè po anestezijos ir operacijos jau operacinejje ir noras kuo greičiau patekti ị ịprastinę profilinę palatą). Literatūroje pažymima, kad pacientų nuomonè, išreikšta remiantis šiuo klausimynu, svarbi ir ligoninès personalui, nes padeda gerinti paslaugų kokybę [11].

\section{Išvados}

1. QoR-15 klausimynas yra paprastas, lengvai suvokiamas, greitai užpildomas ir tinkamas įvertinti paciento atsigavimo kokybès lygmeni ankstyvuoju poanesteziniu ir pooperaciniu periodu.

2. Apklausiant pacientus po anestezijų ir ịvairių operacijų, nustatytas puikus ir geras atsigavimo kokybės lygmuo ankstyvuoju pooperaciniu periodu poanestezinès priežiūros palatoje.

3. Dažniausi nusiskundimai, lèmę blogesnị atsigavimo kokybès lygmens ịvertinimą, buvo pykinimas, vėmimas, liūdesys, slogi nuotaika, vidutinio stiprumo skausmas.

4. Mūsų tirti pacientai teigiamai vertino jų siuntimą i PAPP poanesteziniam atsigavimui ir išreiške pritarimą PAPP reikalingumui.

\section{Literatūra}

1. Traškaitė V., Urbanaitė D., Stašaitis K., Trepenaitis D., Macas A. Poanestezinès priežiūros, intensyviosios terapijos ir intensyviosios priežiūros paslaugos. Sveikatos mokslai, 2015;25(6):87-93.

https://doi.org/10.5200/sm-hs.2015.123

2. Stark PA, Myles PS, Burke JA. Development and psychometric evaluation of a postoperative quality of recovery score. The QoR-15. Anesthesiology 2013;118(6):1332-40.

https://doi.org/10.1097/ALN.0b013e318289b84b

3. Kleif J, Waage J, Christensen KB, Gogenur I. Systematic review of the QoR-15 score, a patient-reported outcomemeasure measuring quality of recovery after surgery and anesthesia. BJA 2018;120(1):28-36.

https://doi.org/10.1016/j.bja.2017.11.013

4. Gornall BF, Myles PS, Smith CL, Burke JA, Leslie K, Pereira $\mathrm{MJ}$ et al. Measurement of guality of recovery using the QoR40: a quantitave systematis review. BJA 2013; 111(2):161-9. https://doi.org/10.1093/bja/aet014

5. Terwee CB, Prinsen CAC, Ricci Garotti MG, Suman A, de Vet HCW, Mokking LB. The quality of systematic reviews of health-related outcome measurement instruments. Qual Life Res 2016; 25:767-79.

https://doi.org/10.1007/s11136-015-1122-4 
6. Vivas JP, Reyes E, Rios F, Lozano R, Perez JA, Plazas M. Measurement of satisfaction with anesthetic recovery in a high-complexity postanesthetic care unit: apatient perspective. Columbian Journal of Anesthesiology 2018; 46(4):279-85. https://doi.org/10.1097/CJ9.0000000000000070

7. Bowyer A, Jakobsson J, Ljungqvist o, Royse C. A review of the scope and measurement of postoperative quality of recovery. Anesthesia 2014; 69:1266-78.

https://doi.org/10.1111/anae.12730

8. Chanthong P, Abrishami A, Wong J, Herrera F, Chung F. Systematic review of questionnaires measuring patient satisphaction in anesthesia. Anesthesiology 2009; 110:1061-7.

https://doi.org/10.1097/ALN.0b013e31819db079

9. Kleif J, Gogenur I. Severity classification of the quality of recovery-15 score - an observational study. Journal of Surgical Research 2018; 225:101-7.

https://doi.org/10.1016/j.jss.2017.12.040

10. Chazapis M, Walker EMK, Rooms MA, Kamming D, Moonesinghe SR. Measuring quality of recovery-15 after day case surgery. BJA 2016; 116(2):241-8.

https://doi.org/10.1093/bja/aev413

11. Bowyer A, Royse C. The importance of postoperative quality of recovery: influences, assesment, and clinical and prognostic implications. Can J Anesth 2016; 63:176-83.

https://doi.org/10.1007/s12630-015-0508-7

12. McGrath B, Chung F. Postoperative recovery and discharge. Anesthesiology Clin N Am 2003; 21:367-86.

https://doi.org/10.1016/S0889-8537(02)00080-9

13. Davidson KW, Shaffer JA, Ye S, Falzon L, Emeruwa IO, Sunquist K et al. Interventions to improve hospital patient satisfaction with healthcare providers and systems: a systematic revew. BMJ 2017; (7):596-606.

https://doi.org/10.1136/bmjqs-2015-004758

14. Sa AC, Sousa G, Santos A, Santos C, Abelha FJ. Quality of recovery after anesthesia: validation of the portuquese versijon of the "Quality of Recovery 15" questionnaire. Acta Med Port 2015; (5):567-74.

https://doi.org/10.20344/amp.6129

15. Lin C, Prozesky J, Martin DE, Cherian VT. Patient's expectations of their anesthesiologists. AJMC 2019; 25(10):e304-e309.

16. Andemeskel YM, Elsholz T, Gebreyohannes G, Tesfamariam EH. Patient satisphaction with peri-operative anesthesia care and associated factors at two National referral hospitals: a cross sectional study in Eritrea. BMC 2019;19:669-78.

https://doi.org/10.1186/s12913-019-4499-x

17. Sarkar M, Rock P, Rowen L, Hong C. Increased patient satisfaction in the postanesthesia care unit with the implementation of a controlled noise reduction program. J Perianesth Nurs 2021;36(1):3-7.

https://doi.org/10.1016/j.jopan.2020.05.001
QUALITY OF RECOVERY (QoR-15) ASSESSMENT IN POST-ANAESTHESIA CARE UNIT AFTER UROLOGICAL AND EAR, NOSEAND THROAT SURGERY

\section{E. Glumbakaitè, V. Ragaišis, A. Macas}

Keywords: anaesthesia, adult patients' recovery, QoR-15 questionnaire, post-anaesthesia care, surgery, quality assessment.

Summary

After urological and ear, nose and throat (ENT) surgery patients are transferred to the post-anaesthesia care unit (PACU) because of high risk of complications and high density of patients in intensive care units. Feedback from patients about quality of recovery is crucial for improving the quality of health care in the PACU. The present observational study intended to evaluate patients' feedback on the quality of their recovery in the PACU after urological and ENT surgery. The study reports the results from 150 patients who were surveyed using quality of recovery (QoR-15) questionnaire in the early postoperative period. The questionnaire included questions about the respondents' experience in the PACU with regard to their ability to breath easily, enjoy food, to have a good rest and sleep, to use the toilet, take care of the personal hygiene and to communicate with the family. Patients also were asked to indicate the degree of their satisfaction with the support from hospital doctors and nurses, the ability to return to usual activities, the experience of feeling in control, as well aspects such as pain, nausea/vomiting and feeling sad or depressed. Following literature on the subject, QoR-15 quantitative data were transformed into qualitative scale: excellent, good, moderate, poor recovery. The data were collected from October 2019 to February 2020. The results were described by average with the standard deviation, absolute numbers and percentages. The surveyed patient group included $63(42 \%)$ men and $87(58 \%)$ women. The average age was 54.59 (19.79) years. The best results were for the following quality of recovery criteria: to be able to breathe easily, to enjoy food, to have a good rest and sleep, to use the toilet, to take care of personal hygiene, to communicate with the family, to feel supported by hospital doctors and nurses, to be able to return to usual activities and to feel being in control. The surveyed patients also indicated that they did not feel severe pain and did not feel depressed. Conversely, moderate pain, nausea/vomiting and feeling sad received lowest scores. Respectively, quality of recovery of 138 patients $(92 \%)$ was identified as good, $10(7 \%)$ as excellent, and 1 $(0.6 \%)$ as moderate. None of the patients were in the group of poor recovery. $135(90 \%)$ of adult patients were positive about the necessity of the PACU, whereas $15(10 \%)$ believed that the PACU is not necessary. To conclude, QoR-15 questionnaire is a user friendly and relevant tool to evaluate post-anesthesia quality of recovery. As the study revealed, the quality of recovery was excellent, good or moderate. Lower quality of recovery scores were frequently linked to moderate pain, nausea/vomiting and feeling sad or depressed. Overall, the surveyed patients regarded the PACU as indispensible for post-anaesthesia recovery.

Correspondence to: egle.glumbakaite@gmail.com

Gauta 2021-03-26 